\title{
Quality Management Systems in Meat Processing Industry in Albania - Quantifying Factors that Influence its Implementation
}

\author{
PhD. Ilir Kapaj \\ Prof. As. Dr. Ana Mane Kapaj \\ Dr. Etleva Dashi Muca
}

Agriculture University of Tirana, Faculty of Economy and Agribusiness, Albania

Doi:10.5901/mjss.2013.v4n10p470

\begin{abstract}
The attention in this study is focused on the management and particularly on products quality and safety issues in the level of businesses. More specifically, this research investigates factors that influence willingness of meat processing enterprises in Albania to invest on internationally recognized quality management standards (ISO). Objective of this research is to investigate how two attitudes of meat processing enterprises in Albania; 'Willingness to invest on ISO' and 'Perception about competition level' are affected by different factors belonging to internal and external environment of the organization. Stratified random sampling was used for selecting the sample of 45 meat processing enterprises out of 54 officially registered. Face to face interview survey method was conducted. The respondents were mainly managers, owners or high level personnel of the selected meat enterprises. The model of ordinal logistic regression was used to quantify the effects of different management factors on 'Willingness to invest on ISO'. As result we conclude that the more information and knowledge enterprises have about ISO standards, the more they will have the willingness to invest on these standards. The next finding is that, if companies want to operate in national markets (high competition level) it is a good choice to do a benchmark analysis, also if enterprises in meat industry want to operate in high competitive markets they have to focus on after sales services and on product delivery.
\end{abstract}

\section{Introduction}

In the last 10 years the most drastic change in quality thinking is probably the change from production-oriented to consumer-oriented concepts. Moreover, integrative approaches, system thinking, the focus on advanced technologies and belief in human capacities have had a considerable impact on current quality management. (Schiefer 2002) Quality has become a vital distinctive feature for competition in the world market food products. To obtain a good quality end product, quality is more and more managed along the whole food chain from the supplier of raw materials to the consumption. Striving for quality is not a free choice. Although before the nineties there existed a good tradition, the current industry of the meat processing is a relatively new industry in Albania, established mainly in these last 15 years. Exploiting all the possibilities and the resources and overcoming the difficulties faced during development, it has always managed to satisfy the quantitative needs of the Albanian consumers. Nowadays the most important and delicate problem related to meat processing industry is the quality and safety of these products (avoiding elements in the content of these products that damage and endanger the health). This problem is becoming more sensitive as the meat industry is starting to prepare for introducing its products in a larger and more organized way in the foreign markets, but firstly in the European market. In this study we are going to identify the factors that have an effect on implementing quality management standards by meat processing sector in Albania and also to quantify these effects.

This research will consist in the identification and measurement of factors that influence 'Willingness to invest on ISO' in meat processing industry in Albania. On the other hand managers based on this scientific research can orient their managerial efforts towards improving aspects of quality management. In this research most of our data are going to be ordinal data that have more than two categories. Multicategory logit models that deal with ordinal responses, assume that at each combination of the levels of explanatory variables, the response counts for the categories of $Y$ have a multinominal distribution. This generalization of the binomial applies when the number of response categories exceeds two (Agresti 1996:205). The core point of all multivariate techniques or models is to find if there is any association between dependent variables and independent variables, and if it is, measure the strength of the relationship. We will use the SPSS Ordinal Regression Procedure, or PLUM (Polytomous Universal Model), which is an extension of the 
general linear model to ordinal categorical data. We can specify five link functions as well as scaling parameters. The procedure can be used to fit heteroscedastic probit and logit models (Norušis 2008:69).

We will consider as dependent variable the categorical variables measured in Likert scale "Willingness to invest on ISO standards" (high, level of competition leading to an immediate need for quality improvement). As independent variables we will choose like "Level of knowledge about ISO standards", "Willingness to invest on training", "Operational markets", "Ration Export/annual turnover", "Level of compiling product technical specification", "Collaboration with R\&D department within organization", Benchmarking' etc. According to Agresti (1996) the measurement scale of independent variables in ordinal Logistic Regression can be of any type as it is in our case (nominal, interval, ordinal and ratio scale).

\section{Results}

We considered in the beginning the attitude of meat procesing enterprises in Albania towards investing in implementing widely recognized quality management systems and to be more specific we choose as dependent variables 'Willingness to invest in implementing ISO series' (1= Fully known, 2= Mostly known, $3=$ Medium known , $4=$ Poorly known, $5=$ Not known). By using the correlation matrix in SPSS we tried as many as 15 potential independent variables for finding any significant correlation, between dependent and independent variables. Although there were more than four variables that are correlated with dependent variable we couldn't found reliable regression model significance for all of them, but we found for four of them. So, as independent variables are considered the following variables

(a) Percentage of the export in relation to the annual turnover of the company $(1=$ Under $10 \%, 2=10 \%-30 \%, 3=$ $31 \%-50 \%, 4=$ Over $50 \%, 5=$ No export), (b) Operational markets of your organization (nominal variable coded $1=\ln$ the local markets, 2 = In national markets, 3 = International markets, 4= All markets), (c) Company's willingness to invest for training regarding quality management $(1=Y e s, 2=$ No, $3=$ Partially, $4=$ No answer), (d) Level of knowledge about ISO 9001:2000 (1= Fully known, 2= Mostly known, $3=$ Medium known , 4 = Poorly known, $5=$ Not known).

Table 1: Relationships between 'Willingness to invest on ISO' and four different QM variables

\begin{tabular}{lcccc}
\hline Willingness to invest on ISO & $\begin{array}{c}\text { Export/ annual } \\
\text { turnover (\%)(a) }\end{array}$ & $\begin{array}{c}\text { Operational } \\
\text { markets (b) }\end{array}$ & $\begin{array}{c}\text { Willingness to invest } \\
\text { for training (c) }\end{array}$ & $\begin{array}{c}\text { Knowing ISO } \\
9001(\mathrm{~d})\end{array}$ \\
\hline Correlation coefficient & $0.445^{\star \star}$ & $-0.232^{*}$ & $0.229^{\star}$ & $0.667^{\star *}$ \\
Significance (2-tailed) & 0.000 & 0.029 & 0.039 & 0.000 \\
$\mathrm{~N}$ & 43 & 45 & 44 & 45 \\
\hline -2 Log-Likelihood & 45.949 & 16.044 & 32.228 & 59.622 \\
Chi-Square & 16.931 & 6.114 & 7.003 & 58.066 \\
Degree of freedom & 3 & 2 & 2 & 4 \\
Significance & 0.001 & 0.047 & 0.030 & 0.000 \\
\hline Nagelkerke & 0.204 & 0.090 & 0.086 & 0.504 \\
\hline Parameter estimate & -1.840 & 0.936 & -0.396 & -2.147 \\
Wald statistics & 14.884 & 4.765 & 0.185 & 8.526 \\
Significance & 0.000 & 0.029 & 0.617 & 0.004 \\
\hline Exp (b) Odds ratio & 0.159 & 2.549 & $\mathrm{NA}$ & 0.011 \\
\hline
\end{tabular}

Source: Own calculation and data

a) Having a ratio of export/annual turnover les than $10 \%$ (1= less than 10\% most of the enterprises not export at all) (Table 1) nis associated with likelihood of scoring 1 in the independent variable (Full willingness to invest on ISO standards $=1$ ) compare to scoring 2 (moderate willingness $=2$ ) by a factor of 0.159 . In other words, the lower ratio export/annual turnovers companies (scoring 1 ) the enterprises are more likely to have full willingness to invest for apply ISO quality management systems. Companies that have higher ratio export/annual turnover (scoring to the levels higher than 1), seems to lack willingness to invest. This behavior can be explained with the fact that since they export, they fulfill a certain quality management standards for export (perhaps ISO or other standards) and don't need to invest in ISO.

b) Independent variable 'Operational Markets: parameters estimate 0.936. Operating in the local markets is associated with higher levels in dependent variable means, lack of willingness to invest on ISO (Table 1). Interesting is that as more enterprises expand the operational markets (going to the higher scoring levels), the chances that they will have the willingness to invest on ISO increase by a factor of 2.549 . 
Conclusion: As meat processing enterprises in Albania expand their operational markets it is more likely that they will have the willingness to invest in quality management standards. The logic behind this behavior make sense, if market become more competitive market, companies have to improve their quality to survive in that market.

Independent variables (c) and (d) have parameters estimate respectively -0.396 and -2.147 . Both are associated with lower scores in dependent, means higher willingness to invest on ISO. Although the parameter estimates for the variable (c) it is not significant $(p>0.05)$ we can still say that the companies that have the willingness to invest on training have also the willingness to invest on ISO. For variable (d), it is interesting how strong is the effect size (Nagelkerke 0.504) between willingness to invest on ISO and level of knowledge about ISO standards. Nagelkerke coefficients vary from 0.086 to 0.504 representing weak to strong effect sizes.

Conclusion: As result we conclude that the more information and knowledge enterprises have about ISO standards, the more they will have the willingness to invest on these standards.

\section{Conclusions and discussion}

According to the results from this study we came to the conclusion that meat processing enterprises have to invest on training with respect to quality and also have to invest in expertise and knowledge about ISO quality management systems. Also they have to expand their operational markets by food industry enterprises in Albania will results in higher attitude towards willingness to invest on ISO quality management systems.

If the companies want to operate in national markets (high competition level) it is a good choice to do a benchmark analysis and if the enterprises in the food industry want to operate in high competitive markets the have to focus on after sales services and on product delivery. Also they must apply client technical specification, compile inter-operational specifications and have a good collaboration between sectors in their organization, in order to enter in high competitive markets.

\section{References}

Agresti, Alan. 2002. Categorical data analysis. Wiley series in probability and statistics. 2nd ed. New York: Wiley-Interscience. Dillman, D. A., (1978). Mail and Telephone Surveys. The Total Design Method. New York: Wiley.

Hair, Joseph F. 2006. Multivariate data analysis. 6th ed. Upper Saddle River, N.J.: Pearson Prentice Hall.

INSTAT, (Institute of Statistics), (2009). Statistical Yearbook 2004. Tirana, Albania.

Kapaj, I. (2004). Assessing the quality and safety of the meat processing industry in Albania. Master theses. Stuttgart/ Germany

Luning, L.A., Marcelis, W.J. and Jorgen, W.M.F., (2002). Food Quality Management: a Techno Managerial Approach. Wageningen Pers, Wageningen, Netherlands.

Ministry of Agriculture Food and Consumer Protection. 2009, . Database for registered food and beverage enterprises in Albania. MoAFCP, Tirana.

2008. Database for registered food and beverage enterprises in Albania. MoAFCP, Tirana.

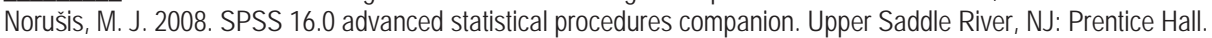

Schiefer, Gerhard. 2002. Quality management in agriculture and food: Management principles, system requirements, and development directions. 2. Aufl. ed. Vol. 94,2. Bonn: ILB. 